\title{
X-ray diffraction study of epitaxial zinc and cadmium films prepared by hot-wall technique
}

\author{
A V KULKARNI and R PRATAP* \\ D B J College, Chiplun 415605 , India \\ *Department of Physics, University of Bombay, Vidyanagari, Bombay 400 098, India \\ MS received 12 May 1986
}

\begin{abstract}
Hot-wall technique greatly improves the quality of zinc and cadmium films deposited on glass substrate. At substrate temperature the growth of such films is well ordered, showing highly preferred orientation along c-axis. However, if the substrate temperature is increased beyond certain limit, we get polycrystalline growth of the films. This shows that the growth of zinc and cadmium films on glass substrate strongly depends on the substrate temperature.
\end{abstract}

Keywords. X-ray diffraction; epitaxial growth; hot-wall technique; zinc films; cadmium films.

\section{Introduction}

The conventional method of vacuum deposition of cadmium films does not give good quality homogeneous films deposited on glass substrate (Bandopadhyay and Pal 1979). We have already shown that, by using the hot-wall technique, good quality cadmium films consisting of large crystal domains with only [002] orientation, can be obtained (Kulkarni et al 1984). The present paper reports the effect of elevated substrate temperature on the epitaxial growth of zinc as well as cadmium films. The growth process is strongly influenced by the temperature as well as the nature of the substrate. Cadmium films deposited on $\mathrm{NaCl}(100)$ single crystal substrate show preferred orientations in [101], [102], [103] and [002] directions in decreasing order (Kulkarni et al 1984). The polycrystalline nature of the films deposited on this substrate is due to the lattice mismatch and relative positioning of cadmium atoms (Chopra 1969). However, if an amorphous substrate like glass is used, the lattice mismatch plays a smaller role in the growth process. After initial deposition of few atomic layers of the film, the auto-epitaxy plays an important role in further development of the film structure. Thus, we get ordered structure with highly preferred orientation. It is also observed that a vacuum of the order of $10^{-5}$ torr is suitable for such growth.

\section{Experimental}

The apparatus used to deposit cadmium and zinc films was essentially the same as described earlier (Kulkarni et al 1984). The only modification was to replace corning glass tube with quartz tube having larger dimensions (height $6.0 \mathrm{~cm}$; outer dia. $2.9 \mathrm{~cm}$; inner dia. $2.6 \mathrm{~cm}$ ). Cadmium metal (purity $6 \mathrm{~N}$ ) (obtained from Koch-Light Laboratories, UK) and zinc metal (purity, 5N) (from Fluk A G, Buchs, Switzerland) were used as source material for depositing the films. The vacuum during deposition 
was maintained at $2 \times 10^{-5}$ torr. Cleaned glass substrates were used to deposit all the films. The thickness of the films was determined by gravimetric method and for the purpose a Mettler, M5, balance with sensitivity $1 \mu \mathrm{g}$ was used.

\section{Results and Discussion}

Visual observation showed that all the films deposited on the glass were continuous and shining like mirror at the back of the films, while the front surfaces had silverywhite shine. To understand the film structure, $x$-ray diffractometry was carried out using fully computerised, SIEMENS-RE 2400 diffractometer. During $x$-ray scanning, the sample was kept rotating at a constant speed of $30 \mathrm{rev} / \mathrm{min}$ about an axis perpendicular to its plane and passing through its centre. This gave an overall picture of the complete film structure.

Figure 1 shows the XRD patterns of cadmium and zinc films deposited by HWT at different substrate temperatures. Tables 1 and 2 give the relative intensities of the

Table 1. X-ray diffraction measurement on cadmium films prepared by HWT on glass substrate.

\begin{tabular}{lccc}
\hline & \multicolumn{3}{c}{ Relative intensity (\%) } \\
\cline { 2 - 4 } hkl & $70^{\circ}<\mathrm{Ts} * 80^{\circ} \mathrm{C}$ & $100^{\circ}<\mathrm{Ts}<110^{\circ} \mathrm{C}$ & ASTM-data \\
\hline 002 & 100 & 100 & 65 \\
100 & - & $2 \cdot 5$ & 32 \\
101 & - & $32 \cdot 2$ & 100 \\
102 & - & $12.4\left(\mathrm{~K} \alpha_{1}\right)$ & 32 \\
102 & - & $6.7\left(\mathrm{~K} \alpha_{2}\right)$ & - \\
103 & - & $15.4\left(\mathrm{~K} \alpha_{1}\right)$ & 26 \\
103 & - & $8.3\left(\mathrm{~K} \alpha_{2}\right)$ & - \\
004 & $9.4\left(\mathrm{~K} \alpha_{1}\right)$ & $23.5\left(\mathrm{~K} \alpha_{1}\right)$ & 3 \\
004 & $5.0\left(\mathrm{~K} \alpha_{2}\right)$ & $12.3\left(\mathrm{~K} \alpha_{2}\right)$ & - \\
\hline
\end{tabular}

${ }^{*} T_{s}$, Substrate temperature.

Table 2. X-ray diffaction measurement on zinc films prepared by HWT on glass substrate.

\begin{tabular}{lccc}
\hline & \multicolumn{3}{c}{ Relative intensity $(\%)$} \\
\cline { 2 - 4 } hkl & $40^{\circ}<\mathrm{Ts}<50^{\circ} \mathrm{C}$ & $60^{\circ}<\mathrm{Ts}<70^{\circ}$ & ASTM-data \\
\hline 002 & 100 & 100 & 53 \\
100 & $0 \cdot 4$ & $0 \cdot 7$ & 40 \\
101 & $0 \cdot 2$ & $1.9\left(\mathrm{~K} \alpha_{1}\right)$ & 100 \\
101 & - & $1 \cdot 1\left(\mathrm{~K} \alpha_{2}\right)$ & - \\
102 & - & $2 \cdot 6\left(\mathrm{~K} \alpha_{1}\right)$ & 28 \\
102 & - & $1 \cdot 6\left(\mathrm{~K} \alpha_{2}\right)$ & - \\
103 & $0 \cdot 1$ & $4 \cdot 1\left(\mathrm{~K} \alpha_{1}\right)$ & 25 \\
103 & - & $2 \cdot 2\left(\mathrm{~K} \alpha_{2}\right)$ & - \\
110 & - & $0 \cdot 2$ & 21 \\
004 & $9 \cdot 4\left(\mathrm{~K} \alpha_{1}\right)$ & $17 \cdot 6\left(\mathrm{~K} \alpha_{1}\right)$ & 2 \\
004 & $4 \cdot 7\left(\mathrm{~K} \alpha_{2}\right)$ & $10 \cdot 2\left(\mathrm{~K} \alpha_{2}\right)$ & - \\
112 & - & $0 \cdot 7$ & 23 \\
200 & - & $0 \cdot 2$ & 5 \\
\hline
\end{tabular}




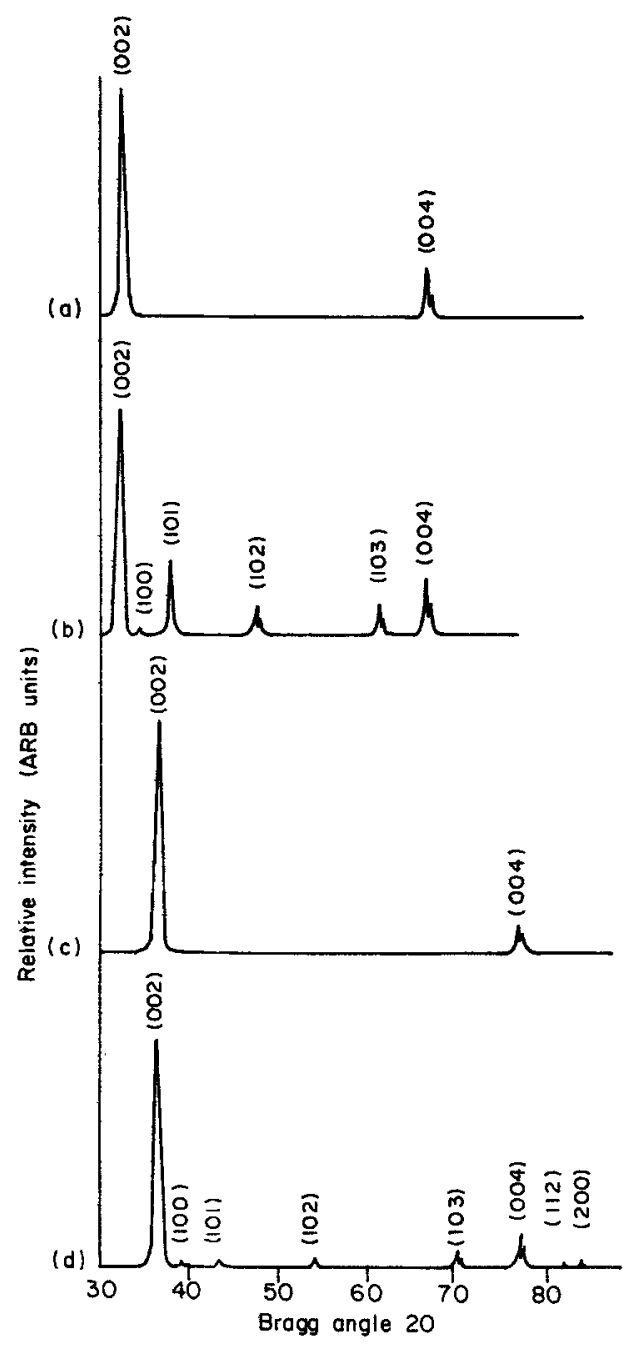

Figure 1. X-ray diffraction pattern (obtained with $\mathrm{CuK} \alpha$ radiation) for the films deposited onto glass substrate by HWT. (a) $\mathrm{Cd}$ film $\left(70^{\circ}<T_{s}<80^{\circ} \mathrm{C}\right)$; (b) $\mathrm{Cd}$ film $\left(100^{\circ}<T_{s}<110^{\circ} \mathrm{C}\right)$; (c) $\mathrm{Zn}$ film $\left(40^{\circ}<T_{s}<50^{\circ} \mathrm{C}\right)$ : (d) $\mathrm{Zn}$ film $\left(60^{\circ}<T_{s}<70^{\circ} \mathrm{C}\right) . T_{s}=$ substrate temperature.

peaks observed for cadmium and zinc films respectively. Figures $1 \mathrm{a}, \mathrm{c}$ indicate that the film structure is well ordered with perfect epitaxial growth along [002] direction. The diffraction pattern at elevated substrate temperature $\left(100-110^{\circ} \mathrm{C}\right)$ clearly shows the appearance of Cd peaks corresponding to the planes (100), (101) and so on (figure 1b). This shows that cadmium films deposited at elevated temperature (approximately greater than one third of the melting point of the metal) are polycrystalline.

Similar trend is observed in zinc films deposited at higher substrate temperature $\left(60-70^{\circ} \mathrm{C}\right)$ (figure $1 \mathrm{~d}$ ), the newly appeared reflection peaks (showing polycrystalline nature of the film) have very low intensity. Such preferentially oriented growth of zinc films along [002] direction has also been reported in the thickness range 500-5000 $\AA$ (Nandi et al 1978). But the perfect epitaxial growth (figure 1c) in zinc films 
Table 3. Deposition parameters of the films prepared by HWT

\begin{tabular}{|c|c|c|c|c|c|}
\hline \multirow[b]{2}{*}{ Film } & \multicolumn{3}{|c|}{ Temperature $\left({ }^{\circ} \mathrm{C}\right)$} & \multirow{2}{*}{$\begin{array}{l}\text { Thickness } \\
(\mu \mathrm{m})\end{array}$} & \multirow{2}{*}{$\begin{array}{c}\text { Growth rate } \\
(\mu \mathrm{m} / \mathrm{hr})\end{array}$} \\
\hline & Source & Wall & Substrate & & \\
\hline $\mathrm{Cd}$ & $400-450$ & $375-425$ & $70-80$ & $5 \cdot 2$ & 25 \\
\hline $\mathrm{Cd}$ & $450-500$ & $400-450$ & $100-110$ & $4 \cdot 5$ & 35 \\
\hline $\mathrm{Zn}$ & $500-550$ & $300-400$ & $40-50$ & 6.5 & 39 \\
\hline $\mathrm{Zn}$ & $550-600$ & $350-450$ & $60-70$ & $2 \cdot 3$ & 45 \\
\hline
\end{tabular}

has been observed for the first time in thick films at the substrate temperature $40-50^{\circ} \mathrm{C}$.

Table 3 gives the deposition parameters for cadmium and zinc films. The films are thick, the thickness being in the range 2 to $6 \mu \mathrm{m}$. The rate of deposition is in the range of 25 to $45 \mu \mathrm{m} / \mathrm{hr}$. Single heating coil was used to heat the quartz tube and therefore, the source and wall temperatures could not be precisely defined. The glass substrate was radiation-heated from the same heating coil.

\section{Conclusion}

By using hot-wall technique, thick zinc and cadmium films having perfect orientation can be deposited on glass substrate, keeping the substrate temperature sufficiently low (below one third of the melting point of the metal). We have also shown that such films usually consist of large crystallites $(\sim 5 \mu \mathrm{m})$ (Kulkarni et al 1984). Thus, this simple version of HWT is useful wherever highly epitaxial on (even thick) films of cadmium and zinc are required.

\section{Acknowledgements}

The diffractometer facility was provided by the Tata Institute of Fundamental Research, Bombay. One of us (AVK) gratefully acknowledge the fellowship awarded by the University Grants Commission, New Delhi. The authorities of DBJ College, Chiplun, were kind enough to grant AVK the necessary study leave to take up the fellowship.

\section{References}

Bandopadhyay S K and Pal A K 1979 J. Mater. Sci, 142989

Chopra K L 1969 Thin-film phenomena (New York: McGraw-Hill) 226

Kulkarni A V, Bose S and Pratap R 1984 Thin Solid Films 120 L73-L77

Nandi R K, Suchitra Sen and Sen-Gupta P 1978 Thin Solid Films 51141 